\title{
Investigating reliability centered maintenance (RCM) for public road mass transportation vehicles
}

\author{
James Hopkinson, Noel Perera , Evran Kiazim \\ Department of Mechanical and Construction Engineering, Faculty of Engineering and Environment, Northumbria University, Wynne Jones \\ Building, Newcastle Upon Tyne, NE1 8ST,England
}

\begin{abstract}
Presently public road mass transportation organisations maintain their vehicles using scheduled corrective maintenance which is carried out at the discretion of the organisation. Operating a corrective maintenance policy means that equipment are allowed to operate to failure and are only repaired or replaced when it fails. Corrective maintenance is generally recognised as an inefficient approach to maintaining equipment as the costs in terms of finance and time can be excessive. In many industries, from aerospace to oil production, a system of reliability centered maintenance (RCM) is utilised. RCM estimates when equipment failure can be expected to occur and ensures that maintenance is performed before it does. Using the RCM approach usually results in assets being more reliable, with low equipment failure rates within its mechanical systems. This often results in significant financial benefit to the organisation as operating equipment become more reliable allowing the vehicles to be in service for longer and achieving higher safety standards. This investigation has predicted that potential equipment failure could take place between the vehicle mileage of $6000-12000$ miles. Using the consecutive reading /sampling method together with a set oil spray diameter size alert value of $130 \mathrm{~mm}$, it was possible to further narrow down the potential equipment failure to a vehicle mileage of 10000 miles.
\end{abstract}

\section{Introduction}

In recent times the public road mass transportation industry has faced challenging demands with respect to its environmental effects, emissions, reliability, safety and commercial competition. In meeting these challenges its important that its workforce and equipment performed daily at its optimum level. One potential option of addressing these challenges was the adoption of the reliability centered maintenance (RCM) approach. A key concept of RCM is reliability which is important for improving safety. Researchers [1,2] have described reliability as "probability that an item will perform a required function without failure under stated conditions for a specified period of time". RCM has existed in industry for over 30 years presenting optimisation of preventive maintenance techniques [3]. RCM was first developed in the airline industry in the late 1960s [4] to address concerns with the introduction of the wide body jets. As maintenance cost started to increase sharply, the airline industry at that time started to become concern that it would be financially unfeasible to use conventional maintenance techniques to maintain aircrafts that were larger and more complex. As conventional maintenance techniques were interval based this further contributed to the increase in maintenance cost relative to the other operating cost
This contributed to the growth of RCM which was based on equipment performance data and criticality. The RCM cost remained approximately the same as the cost of the conventional maintenance techniques however aircraft availability and reliability improved. This was because more attention was devoted to maintaining the equipment that was most likely to fail. Thus the objectives of RCM [5,6] are to reduce maintenance and support cost as well as increase equipment reliability and safety. Developing a maintenance strategy and plan is key to the implementation of RCM within an organisation/ industry. The two possible RCM techniques that can be adopted are preventative and predictive maintenance techniques.

Preventive maintenance is carried out on a working piece of equipment to avoid unanticipated failure. Therefore it is maintenance which is performed frequently to reduce the possibility of equipment failure. The equipment time to failure and trend of failure rate can be monitored to increase the efficiency and cost effectiveness of employing the preventive maintenance strategy. Published work [7] has shown that replacing equipment which has a diminishing failure rate might increase its possibility of failing. However replacing equipment which has a constant failure rate has shown to have no effect on its possibility of failing. On the other hand replacing equipment which has a rising failure rate 
has shown that it can reduce its possibility of failing. This is illustrated in figure 1 showing the bath tub curve for an equipment standard life cycle. Following this preventive maintenance should be carried out on equipment that is in the $3^{\text {rd }}$ section of the bath tub curve i.e. equipment that is in its life cycle period of experiencing increasing failure.

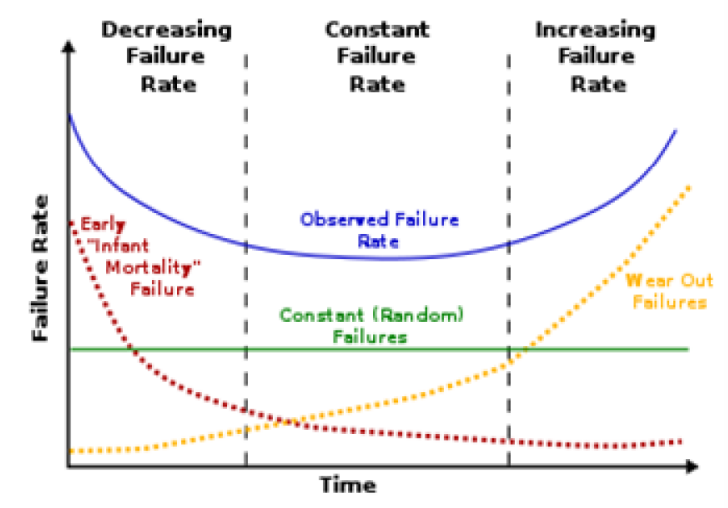

Figure 1. Bath tub curve [5]

Predictive maintenance is carried out to ascertain the working condition of the equipment whilst in operation to predict when maintenance should be performed. Most equipment failure modes are not time dependent but do produce indications that failure is imminent or is occurring. In this case if these indications can be detected it would be possible to identify the failing equipment and take remedial action before it experiences total failure.

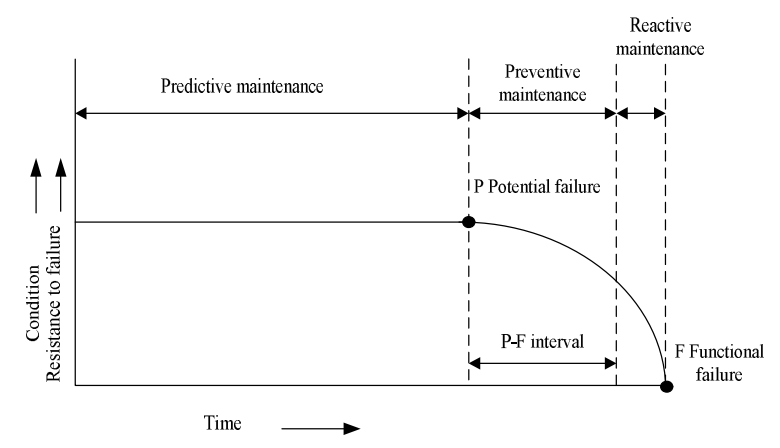

Figure 2. The maintenance potential failure (P-F) curve [8]

Figure 2 above shows the potential failure (P-F) curve which illustrates the point $\mathrm{P}$ where failure can first be detected followed by point $\mathrm{F}$ when failure begins. The point in the failure process where it would be possible to detect whether failure is occurring or about to occur is known as the potential failure, point $P$ [8]. If failure is not detected and addressed at point $\mathrm{P}$ it continues to deteriorate until it reaches point $\mathrm{F}$, functional failure.

Another important aspect of the reliability centered maintenance strategy is the drafting of the reliability programme which identifies all the proactive tasks that have to be completed. Reliability programmes do not react to single events but is utilised to detect system problems and trends that may trigger many other subsequent events [9]. A reliability program must be a written program approved by an Authority. It has to specify responsibilities and procedures within an operator's organisation which will ensure successful implementation of a reliability program. In the reliability programme identified tasks should clearly be recorded as completed by named operator(s), date and time of completion and description of the level of completion. In industry, an operator can vary a number of parameters used. For example pilot complaints per 100 flights, technical delays above 15 minutes per 1000 flights, component replacements per 1000 component flight hours, unscheduled component replacements per 1000 flight hours, engine in flight shut downs and unscheduled changes per 1000 engine hours, repetitive pilot complaints, long lasting technical issues and significant findings during maintenance activities. For all of the measured parameters, an upper control limit or alert value has to be determined. An alert value is used to recognise and react to significant deviations from statistically acceptable limits in reliability. An alert value is a predetermined threshold that triggers an alert. Upper control level or alert value is a statistical value which shows the limit below which deviations are considered statistically acceptable. In the case of an exceeded alert limit value, system reliability is considered to be unstable. An appropriate corrective action must be applied to stop a negative trend due to an alert value being exceeded repeatedly.

\section{Experimental test}

For the purpose of this paper an investigation was carried into the oil contamination of the air braking system of a public road mass transportation vehicle [10]. The braking system on these vehicles operated as a compressed air system. Air was taken in to the system, filtered and compressed and stored in the air reservoirs at a pressure of around 9 bar. The compressed air was then delivered via a control system. The air compressor mechanism was powered via the engine timing gears or a belt running off the crankshaft pulley. This mechanism had to be cooled and lubricated to avoid overheating or seizure. This was achieved through the engines cooling and lubrication system. As the air can contain contaminants such as oil and water, normally due to worn piston rings in the compressor, it had to be funnelled through an air dryer to remove the impurities in the air. This reduced the potential for corrosion and subsequent failure in the air braking system. The pressurised air was then held in a vessel known as the air reservoir tank until it was distributed throughout the system via a 4-way protection valve. This valve channelled the air to the front and rear circuit brake air tanks, parking brake air tank and an air tank for the auxiliary equipment. This air braking system also included safety air release valves to prevent the air lines from becoming over-pressurised and potentially rupturing.

An experimental test was initiated to investigate the effectiveness of the proposed modifications to the air dryers within the air braking system to address the issue of oil contamination. The purpose of this investigation was to identify the most effective modification to the air dryer system to generate the greatest reduction of oil contamination within the air braking system. The most effective modification was then implemented on the fleet 
of this public road mass transportation vehicle. The proposed modifications were:

Modification 1: The air dryer was fitted with an Oil Separator Cartridge (O.S.C.).

Modification 2: $\quad$ Air dryer was overhauled by using Fluorocarbon O-rings where possible.

Modification 3: Air dryer cartridge renewed with standard fitment.

Each modification was applied to one vehicle. For example, modification 1 was applied to Vehicle 1 and modification 2 was applied to Vehicle 2 etc.

\subsection{Test procedure}

In the air braking system the compressed air was stored within the air reservoir which was fabricated with a drain plug. The purpose of this plug was to allow air to be manually purged from the system. It was possible to visually gauge the level of oil contamination in the air system when purging it by measuring the resulting oil spray output from this reservoir. The oil was sprayed onto a piece of paper and the larger the diameter of the oil spray over a fixed distance, the higher the level of oil contamination within the air system. This was known as the blot test. A blot test was carried out every 1000 miles of vehicle operation and the experimental detail is shown in table 1 . The results were then tabulated and plotted as a graph.

Table 1. Experimental detail

\begin{tabular}{|l|l|l|}
\hline $\begin{array}{l}\text { Experiment } \\
1\end{array}$ & $\begin{array}{l}\text { Modification } \\
1:\end{array}$ & $\begin{array}{l}\text { The air dryer was fitted } \\
\text { with an Oil Separator } \\
\text { Cartridge (O.S.C.). }\end{array}$ \\
\hline $\begin{array}{l}\text { Experiment } \\
2\end{array}$ & $\begin{array}{l}\text { Modification } \\
2:\end{array}$ & $\begin{array}{l}\text { Air dryer was } \\
\text { overhauled by using } \\
\text { Fluorocarbon O-rings } \\
\text { where possible. }\end{array}$ \\
\hline $\begin{array}{l}\text { Experiment } \\
3\end{array}$ & $\begin{array}{l}\text { Modification } \\
3:\end{array}$ & $\begin{array}{l}\text { Air dryer cartridge } \\
\text { renewed with standard } \\
\text { fitment. }\end{array}$ \\
\hline
\end{tabular}

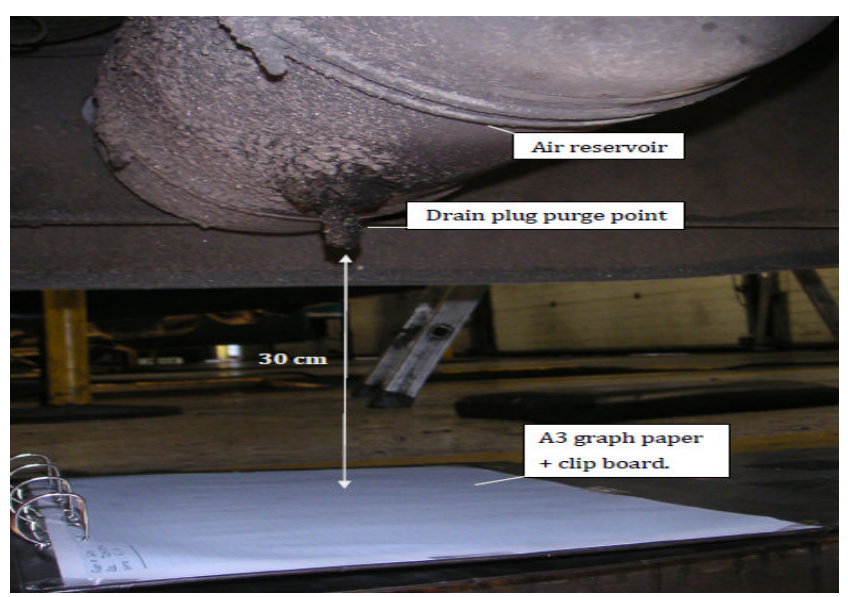

Figure 3. Blot test set up [10]

\section{Results}

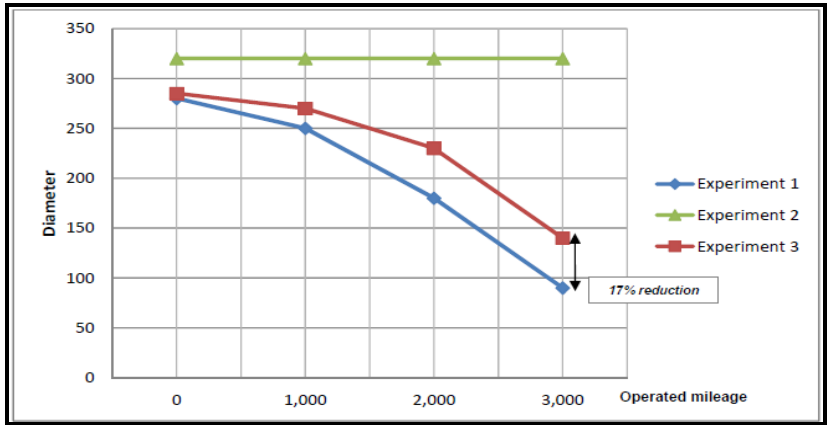

Figure 4. Graph of oil spray diameter vs vehicle operated mileage [10]

It can be deduced from the graph shown in figure 4 that experiment 2 had no effect on the level of oil contamination within the air brake system. However experiments 1 and 3 have had a positive effect on the oil contamination levels. Experiment 1 achieved a 17\% reduction in oil contamination when compared with experiment 3. Experiment 1 and 3 continued to remove the oil contaminants from the air braking system up to an operated mileage of 3000 miles. Hence it can be assumed that if the experiments were allowed to continue beyond 3000 miles, the oil contamination would continue to reduce at a similar rate. However it is anticipated that this trend would continue until the applied modifications could no longer remove any further oil contaminants from the system, causing it to plateaux.

Similar to other equipment within a public road mass transportation vehicle's mechanical system, the oil separator cartridge (O.S.C.) has to be replaced several times within the vehicle's operation period due to degradation and inevitable corrosion. Constant intake of oil contaminants contributed to a build-up of residue in the filter which resulted in performance degradation or equipment failure. The loss of performance in the O.S.C meant that significantly more oil contaminants were able to enter the air braking system potentially damaging it. For that reason, it's essential that the compromised O.S.C cartridge be replaced before significant damage can be caused to the air braking system.

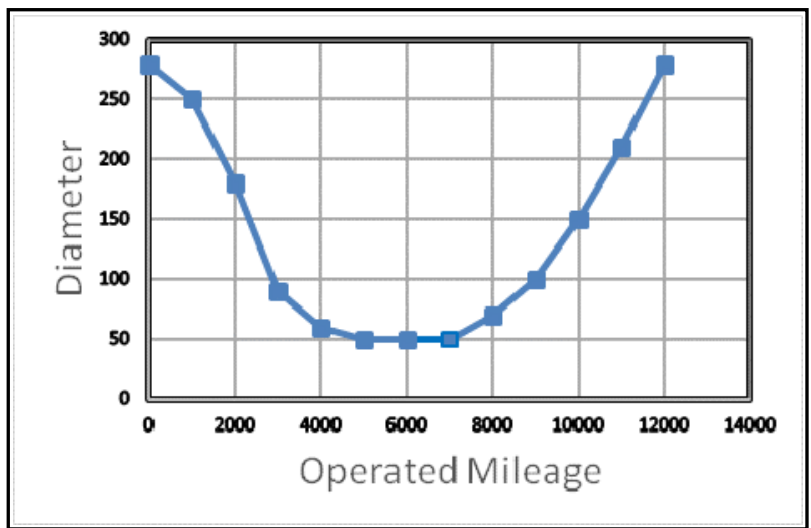

Figure 5. Graph of predicted oil spray diameter vs vehicle operated mileage

The graph showed in figure 5 highlights for experiment 1 the predicted oil spray diameter with respect to the vehicle 
operation mileage over a higher operating mileage. Utilising the bath tub curve methodology, the authors have predicted the possible O.S.C performance beyond the vehicle operated 3000 mileage by extrapolating the experimental data. The extrapolated experimental data highlighted a steady reduction of the oil spray output diameter as it reached a minimum output diameter of $50 \mathrm{~mm}$ at a mileage of 6000 miles. This reduction in the level of the oil contamination can be attributed to the O.S.C performing to its optimum capability. However beyond the 6000 mile point the size of oil spray diameter then began to slowly increase at an accelerated rate till it reached 12000 miles. At this point the extrapolated experimental data showed that the O.S.C would have the same performance level as at the beginning of the experiment.

\section{Discussion of results}

The gradual accelerated increase in the size of the oil spray diameter can be attributed to the impending failure of the O.S.C. The predicted performance of the O.S.C as it began to experience potential failure from the 6000 mile point to its functional failure at the 12000 mile point can provide maintenance engineers with an estimated timeline for scheduling maintenance activities. However it is important to note that the graph shown in figure 5 was based on extrapolated experimental data beyond the vehicle's experimental operating mileage of 3000 miles. Hence the accuracy of the predicted performance of the O.S.C as shown in figure 5 is debateable without a proper validation of the experimental results. The O.S.C should be replaced at any point when it experiences potential failure to functional failure as shown in figure 2. However it not cost effective to replace the O.S.C without first determining whether it's at the end of its service life. Despite experiencing potential failure the O.S.C could still continue to perform at an acceptable level for an indefinite period of time. Also incorrect blot test readings could be recorded leading to the replacement of a potentially perfect performing O.S.C. Therefore to address these issues the outcomes of including the alert value and consecutive reading/sampling techniques were investigated.

For this investigation an alert value was set at the oil spray diameter size of $130 \mathrm{~mm}$ which is shown as a straight horizontal line in the graph in figure 6. During the service life of the O.S.C, the size of the oil spray diameter may start above the alert value but when performing to its optimum capability the size of the oil spray diameter would remain below the alert value. However, as the performance levels of the O.S.C. decreased, the size of the oil spray diameter increased. For a brief period after this occurrence, no maintenance activity was required as the O.S.C. continued to perform at an acceptable level. However, the blot test circled in figure 6 showed that when the size of the oil spray diameter exceeded $130 \mathrm{~mm}$, it triggered the immediate replacement of the O.S.C. Although the alert value could be considered as an effective method, a potential drawback was the possibility that one anomalous result above the alert value could cause the premature replacement of the O.S.C before its failure point.

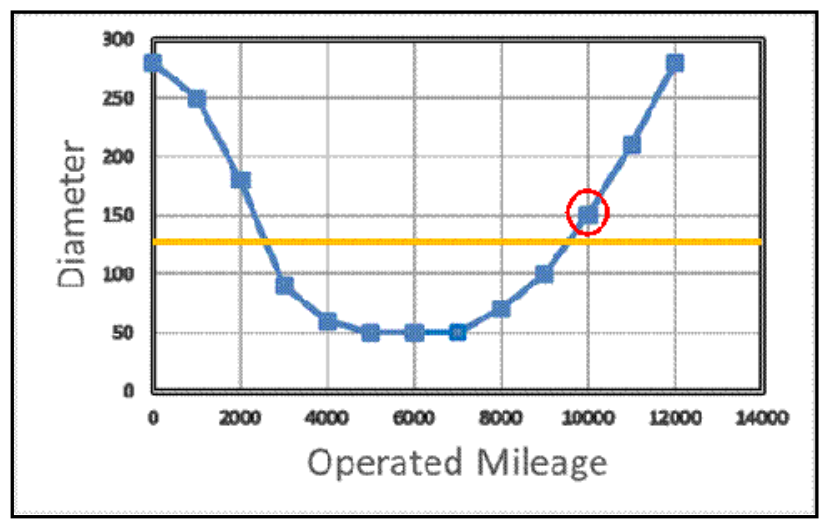

Figure 6. Graph of predicted oil spray diameter vs vehicle operated mileage with indicated alert value

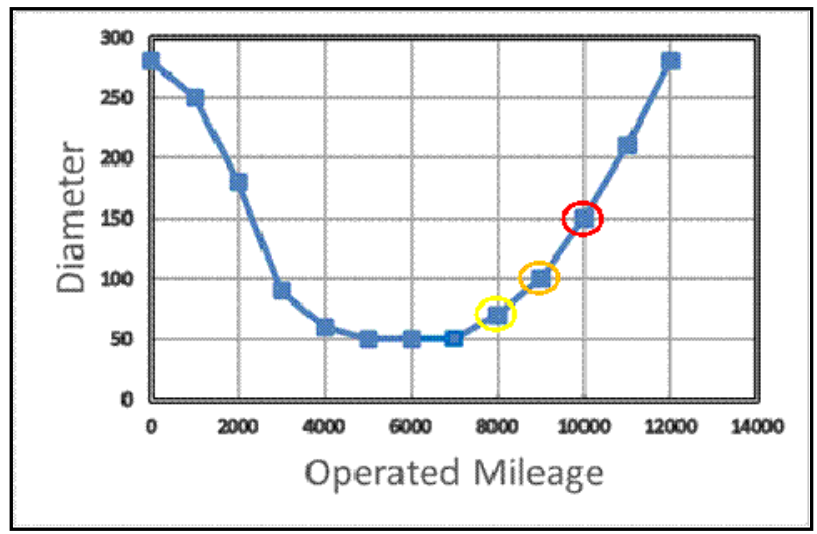

Figure 7. Graph of predicted oil spray diameter vs vehicle operated mileage with highlighted significant blot tests

Using the consecutive reading/sampling method the graph in figure 7 showed the first circled indication of an O.S.C. failure at the 8000 mile point. This is the first indication that the size of the oil spray diameter had increased after the O.S.C. had been performing at its optimum capability. The circled second indication of the O.S.C failure was at the 9000 mile point with an increase in the size of the oil spray. Subsequently the circled third indication of the O.S.C failure was at the 10000 mile point with a further increase in the size of the oil spray diameter. It was at the third indication highlighting 3 consecutive increases in size of the oil spray diameter that triggered the replacement of the failing O.S.C. This method could be considered to be more reliable than the alert value method, as a single anomalous result would not result in the immediate replacement of an O.S.C. performing at an acceptable level. However, this method also has its weakness. Potentially an O.S.C could be replaced if it generated 3 consecutive blot readings showing increasing oil spray diameter sizes. This is despite the increases being comparatively small indicating that the O.S.C was still performing at an acceptable level. 


\section{Conclusion}

The authors have shown the potential effectiveness of implementing a RCM approach in maintaining equipment reliability for the public road mass transportation industry. However the challenges to its implementation are the time and resource implications which equates to additional capital expenditure. With regards to the blot tests, it would take considerable amount of resources to set up, test and record the result of every vehicle at intervals of 1000 miles. Then there is also the added financial implication to the organisation when these vehicles have to be removed from service every 1000 miles. A positive option would be to incorporate the blot test into the interim vehicle maintenance service interval. This would negate the requirement for these vehicles to be removed from service specifically for the blot test.

\section{References}

1. Marquez Garcia F. P., Schmid F. and Collado J. C., A reliability centered approach to remote condition monitoring, Reliability Engineering and System Safety, 80 (1) 33-40 (2003).

2. Dummer, G., Tooley, M., Winton, R., An elementary guide to reliability, Butterworth - Heinemann, Oxford, UK, Chap. 2, (1997)

3. Desphande VS, Modak JP, Application of RCM to a medium scale industry. Reliability Engineering and
System Safety, 77, pp 31-43, (2002).

4. International Atomic Energy Agency (IAEA), Application of Reliability Centred Maintenance to Optimize Operation and Maintenance in Nuclear Power Plants, (May 2007).

5. Bae Chulho, Kim Hyunjun, Son Youngtak, Lee Hoyong, Han Seokyoun, Suh Myungwon, Development of a Web based RCM system for the driverless Rubber-Tired K-AGT system, Journal of Mechanical Science and Technology 23, pp 11421156 (2009)

6. Selvik, JT, Aven, T, A framework for reliability and risk centered maintenance, Reliability Engineering and System Safety, 96, pp 324-331, (2011)

7. O'Connor, P., Practical Reliability Engineering (third edition revised), John Wiley and sons, Chichester, Chap 14 (1997)

8. Moubray, John, Reliability-centered Maintenance, $2^{\text {nd }}$ Edition, Butterworth Heinemann (1997)

9. Zeljko Mausic, Borivoj Galovic, Omer Pita, Optimizing maintenance reliability program for small fleets, Transport, 22:3, 174-177, (2007).

10. Kiazim, Evran, MSc Dissertation, Northumbria University (2014) 